УДК 122/129

DOI 10.19181/2227-8656.2020.1.18

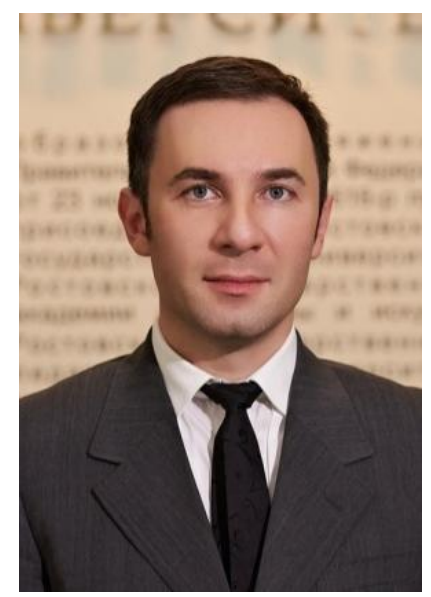

СОЦИАЛЬНЫЕ СМЫСЛЫ РОССИЙСКОГО

ПРОФСОЮЗНОГО ДВИЖЕНИЯ

В СИСТЕМЕ

ВЫСШЕГО ОБРАЗОВАНИЯ:

ИСТОРИЧЕСКИЕ УРОКИ

И СОВРЕМЕННЫЕ ТЕНДЕНЦИИ

\section{SOCIAL MEANINGS OF THE RUSSIAN TRADE UNION MOVEMENT IN THE HIGHER EDUCATION SYSTEM: HISTORICAL LESSONS AND CURRENT TRENDS}


2020 г. профсоюзная организация ЮФУ отмечает 100-летний юбилей. Данная статья призвана обратить внимание на состояние и уровень солидарности работников и обучающихся как в стране, так и в университете, а также наметить направления повышения эффективности работы современных профсоюзов в сфере образования.

Ключевые слова: общественные отношения; солидарность; трудовые права; единство; конфликты; высшее образование; гражданское общество; профсоюз; урегулирование конфликтов.
Union celebrates its 100th anniversary and this article is intended to draw attention to the state of solidarity of employees and students both in the country and at the University, as well as to outline directions for improving the efficiency of modern trade unions in the field of education.

Keywords: social relations; solidarity; labor rights; unity; conflicts; higher education; civil society; Trade Union; conflict resolution.

\section{Введение}

Первичная профсоюзная организация работников и обучающихся Южного федерального университета (далее - ППО ЮФУ) в 2020 г. отмечает сто лет со дня своего создания. Она входит в число первых вузовских организаций, перешедших данный рубеж. В 2019 г. Московский государственный университет им. М.В. Ломоносова широко отметил такой юбилей. На протяжении многих десятилетий ППО ЮФУ находится в авангарде профсоюзного движения в сфере высшего образования. Интерес со стороны профессионального сообщества к генезису профсоюзных организаций связан с тем, что именно они представляют солидарность как социальный феномен. Перманентная институциональная трансформация системы высшего образования ставит новые задачи перед профсоюзными организациями, что актуализирует проблему поиска ответов на вопросы, связанные с содержательным наполнением их деятельности, соответствием исторической повестке дня. Для перехода на траекторию устойчивого развития профсоюзной организации современного вуза важно знать и понимать историю её развития, а также место, которое она занимает в общей системе профсоюзного движения в национальном и глобальном масштабах. Это позволит обеспечить более высокое качество механизмов достижения целевых ориентиров развития профсоюзной организации с учётом динамики социальных запросов, предъявляемых работниками и обучающимися системы высшего образования в интересах настоящих и будущих поколений.

Целью данной статьи являются научно-практическое обобщение опыта развития профсоюзного движения в сфере высшего образования в России, его анализ и определение направлений развития. 


\section{История появления первых профсоюзных организаций}

Первые профсоюзы появились в середине XVIII в. в Англии, в годы промышленной революции. Нужно отметить, что первые ассоциации рабочих имели строго локальный характер и объединяли только высококвалифицированных рабочих наиболее востребованных и передовых отраслей (Нехода, 2010). Деятельность профсоюзов в этот период была нелегальной, что создавало трудности для работы. Однако все принимаемые государством меры уже не могли остановить начатую многочисленными профсоюзными организациями борьбу за права работников, и к 1920 г. в профсоюзах Великобритании состояло около $60 \%$ всех рабочих страны.

В России профсоюзы появились значительно позже, чем в странах Западной Европы. Это было связано с тем, что она долгое время оставалась аграрным государством, где промышленность была развита слабо. В XIX в. с развитием крупного фабрично-заводского производства и формированием рабочего класса появились сообщества, отстаивающие интересы рабочих. Однако до конца XIX в. образование рабочих союзов не допускалось, поэтому так же, как и в других странах, первоначально создаются кассы взаимопомощи, товарищества по экономической поддержке друг друга.

Только к концу XIX в. в России в связи с активным развитием идей солидарности рабочие стали делать первые попытки формирования сообществ по отстаиванию своих трудовых прав. Эти процессы затронули и учительскую сферу. Начальной формой объединения работников образования стали съезды народных учителей. Первый такой съезд был проведен в 1895 г. и имел значение как мероприятие для повышения профессионального уровня работников образования (Скрипникова, 2018).

Десятью годами позже демократически настроенная часть народных учителей уже рассматривали объединение и борьбу с самодержавием как способ устранения невыгодных условий своего труда. И 9 июня 1905 г. было провозглашено создание Всероссийского союза учителей и деятелей по народному образованию, избрано Центральное бюро союза, утвержден устав, который тем не менее исключил политические настроения профессионального сообщества. Но в 1917 г. в программу Всероссийского союза учителей и деятелей по народному образованию была снова включена политическая платформа (Соколов, 1905). После роспуска Учредительного собрания деятельность союза была направлена против действующей власти, но вскоре в союзе про- 
изошел раскол по политическим мотивам, что обусловило выход из него просоветски настроенных членов и создание ими новой организации.

Период формирования и становления профсоюзных организаций в России завершился к лету 1918 г. Первый учредительный съезд Всесоюзного центрального совета профессиональных союзов (ВЦСПС), объединивший впоследствии все профессиональные организации, состоялся в январе 1918 г.

Следующим этапом профсоюзного объединения началось сегментирование по профессиональному признаку, и 29 июля 1919 г. был создан Всероссийский профессиональный союз работников просвещения и социалистической культуры. Необходимо отметить, что после 1920 г. характеристики советских профсоюзов стали резко отличаться от аналогичных институтов за рубежом. Именно тогда профсоюзы были названы «школой коммунизма», т. е. институтом социализации общества, что предопределило характер и направление их деятельности на многие последующие годы.

\section{Современное состояние профсоюзного движения в сфере образования}

Историческая миссия и содержание деятельности профсоюзов в современной России имеют чрезвычайно высокую значимость и признание на общегосударственном уровне, что находит своё подтверждение в ст. 30 Конституции РФ, согласно которой «каждый имеет право на объединение, включая право создавать профессиональные союзы для защиты своих интересов. Свобода деятельности общественных объединений гарантируется», и Ф3 от 12.01.1996 № 10-Ф3 «О профессиональных союзах, их правах и гарантиях деятельности».

На наш взгляд, наличие законодательно закреплённых позиций необходимое, но недостаточное условие для осуществления современными профсоюзными организациями стабильной правозащитной деятельности. Симбиоз целей и содержательного наполнения практической деятельности профсоюзных организаций системы высшего образования требует обращения к онтологическим основам профсоюзной организации как института, формирующего современный образ социальной реальности через преодоление противоречивых начал, свойственных солидарности, её двойственной природы.

В настоящее время профсоюз образования - это мощная организация. Из публичных отчетов Общероссийского профсоюза образования за последние годы можно получить информацию, что в структуре профсоюза образования насчитывается более полутора сотен тысяч 
структурных звеньев. Численность членов профсоюза образования составила более 4 млн чел., из них: более $67 \%$ - работающие; около $30 \%$ - обучающиеся; $3 \%$ - неработающие пенсионеры. Среди работающих педагогические работники составили 57,8 \%, из которых молодёжь до 35 лет - $26 \%$. Общий охват профсоюзным членством - около $74 \%$ (среди работающих - 73,8 \%, среди студентов - 74,1). За сто лет работы профсоюз образования превратился в крупнейшую профсоюзную структуру, имеющую хорошую репутацию и авторитет.

В данной статье постараемся на примере одной первичной организации - Профсоюзной организации работников и обучающихся Южного федерального университета - рассмотреть путь становления и развития профсоюзного движения.

\section{Профсоюзное движение в ЮФУ в 1920-2020 гг.}

Как известно, история Южного федерального университета начинается с 1915 г., когда Императорский Варшавский университет был эвакуирован в город Ростов-на-Дону. Первые годы работы университета были непростыми: адаптация варшавской профессуры на Донской земле, война, революция. В 1917 г. университет был формально упразднен и вновь образован как Донской университет.

Действующая власть пыталась расширить свое влияние и увлечь идеями солидарности как профессорско-преподавательский состав, так и студентов. Это легло на плодородную почву, так как проевропейски настроенная часть преподавателей с радостью восприняли идеи объединения в профсоюзную организацию (Резниченко, 2008). Так в конце 1919 г. началась подготовительная работа по формированию профсоюзной организации Донского университета. В структурных подразделениях формировались местные комитеты. Они объединяли прежде всего нестуденческую часть университета, формируя профсоюз работников. И уже 29 апреля 1920 г. состоялось общее собрание служащих Донского университета для выборов местного профсоюзного комитета, что зафиксировано в протоколе № 1 .

Уже тогда ключевой темой профсоюза стали кадровые вопросы: прием и увольнение, назначения на должности (включая ректора и проректоров) и перемещения, а также вопросы оплаты и охраны труда, оказания помощи в снабжении продовольствием, разрешение трудовых конфликтов, организация общественно полезного труда, культурно-просветительская работа, в том числе участие в вопросе ликвидации неграмотности путем открытия школы для безграмотных и малограмотных служащих. Важным направлением деятельности была по- 
литико-воспитательная работа, в основном посредством чтения публичных лекций. Решали и социальные вопросы сотрудников: отдых, пособия, отведение мест и строительство жилых домов для сотрудников, на основании анкетирования с целью обследования быта сотрудников и определения нуждаемости в улучшении жилищных условий.

ППО ЮФУ прошла все те же структурные преобразования, что и сам университет. В 1925 г. он был переименован в Северо-Кавказский университет. В 1930-1931 гг. из структуры Северо-Кавказского университета была выделена часть подразделений и образованы Медицинский институт, Финансово-экономический институт, Институт промышленности и труда, Институт пищевой промышленности и экономики обмена и распределения, Ростовский-на-Дону педагогический институт. И во всех этих вузах профсоюзная организация СевероКавказского университета стала основой для образования профсоюзных структур в новых учебных заведениях.

Начиная с 2006 г. в развитии профсоюзной организации университета наступил новый этап, который был отмечен процессами конвергенции, когда к Ростовскому государственному университету были присоединены государственные образовательные учреждения высшего профессионального образования - Ростовская государственная академия архитектуры и искусства, Ростовский государственный педагогический университет, Таганрогский государственный радиотехнический университет, был образован Южный федеральный университет. Возникла очевидная необходимость и в её структурной трансформации, что положило начало объединению профсоюзных организаций вузов, вошедших в ЮФУ. Важно отметить, что данный процесс объединения, сменивший разделение, был не менее проблематичным и не ознаменовал собой преодоление противоречий, свойственных системе солидарности как таковой и в приложении к тем системам солидарности работников и обучающихся, которые сформировались на момент объединения в профсоюзных организациях, вошедших в ЮФУ вузов.

В настоящее время ППО ЮФУ состоит из 2821 работника университета, что составляет 60,2 \% от общего количества работников, и 16102 обучающихся (90,7 \%), т. е. объединяет 18932 членов профсоюза.

Основные направления деятельности ППО ЮФУ - это осуществление представительских функций (участие в работе наблюдательного совета университета, ученых советов ЮФУ и структурных подразделений, комиссий, комитетов и рабочих групп в университете и внешних структурах), защита трудовых прав, экспертиза локальных нормативных актов, затрагивающих трудовые и социальные права работни- 
ков и обучающихся, правовое консультирование, ведение социальных программ, материальная помощь, организация отдыха, повышение квалификации профсоюзного актива по новым формам и методам общественной работы, воспитательная работа с молодежью, информационная работа, организация и проведение конференций, круглых столов с целью научного осмысления происходящих в системе образования процессов и выработки солидарных решений по их совершенствованию.

ППО ЮФУ активно взаимодействует с центральным советом Общероссийского профсоюза образования, Федерацией профсоюзов Ростовской области, Ростовской областной организацией Профсоюза работников народного образования и науки РФ. ППО ЮФУ ведет активное международное сотрудничество, являясь членом Евразийской ассоциации профсоюзных организаций университетов (ЕАПОУ) и обмениваясь опытом социальной защиты коллектива. Важными совместными мероприятиями являются проводимые конференции для профсоюзного актива Юга России. А также особую важность приобретают партнерские контакты с Ассоциацией выпускников ЮФУ, среди членов которой депутаты Государственной думы, сенатор Совета Федерации, заместитель министра науки и высшего образования Российской Федерации, председатель и депутаты Законодательного собрания, глава администрации города Ростова-на-Дону, председатель комитета по молодежной политике Ростовской области. В процессе работы напрямую с данными представителями органов власти выстраивается экспертная работа в области трудового законодательства, готовятся проекты нормативных актов в сфере труда научных и педагогических работников, проходят обсуждения наиболее проблемных сфер реализации трудового законодательства и прав на социальное обеспечение, вопросов воспитания молодежи.

Одним из приоритетных правозащитных аспектов деятельности ППО ЮФУ является система выборов профессорскопреподавательского состава, сроки избрания преподавателей, содержание эффективных контрактов, сроки и условия работы научных сотрудников, оплата труда учебно-вспомогательного персонала, стипендиальное обеспечение и условия проживания обучающихся. Профсоюзная организация во многих случаях принимает на себя роль посредника в урегулировании конфликтов между работником или коллективом работников и работодателем, активно участвует в урегулировании споров между участниками образовательных процессов.

Особого внимания заслуживают вопросы совершенствования практики представительства и защиты прав работников - членов 
профсоюза, коллективно-договорной практики. Давно в среде специалистов в области трудового законодательства обсуждается мнение, что социальный пакет, предусмотренный коллективным договором, должен распространяться только на членов профсоюза. В ППО ЮФУ не менее активно обсуждаются вопрос совершенствования содержания эффективного контракта, новые подходы в социальном аудите, а также роль профсоюза в судебной защите своих членов.

На протяжении многих лет хорошо себя зарекомендовал опыт совместного с Институтом социологии и регионоведения ЮФУ проведения социологических исследований, направленных на выявление наиболее острых социальных проблем среди работников и обучающихся, выполнение норм коллективного договора и т.д.

ППО ЮФУ активно взаимодействует с Центром исследования социально-трудовых отношений и проблем профсоюзного движения Института социологии и регионоведения ЮФУ (Сборник материалов ..., 2018). В 2019 г. в ЮФУ была образована междисциплинарная рабочая группа в составе ведущих сотрудников ряда подразделений университета с целью проведения социологического исследования «Социально-профессиональное самочувствие сотрудников ЮФУ: анализ степени удовлетворенности и вовлеченности». Один из блоков вопросов анкеты касался оценки сотрудниками университета эффективности деятельности профсоюза ЮФУ.

В опросе приняли участие более 1600 чел. Около половины из них признали, что обращение в ППО ЮФУ - это эффективный способ защиты трудовых прав. Интересной представляется выявленная в результате опроса тенденция, показывающая, что работников гораздо больше волнуют вопросы защиты их трудовых прав, нежели социальные блага, которые предоставляет профсоюз. Не менее интересно и то, что большая часть сомневающихся в эффективности профсоюза - сотрудники, не являющиеся членами профсоюза. Не получая информации о деятельности организации в полном объеме, эта группа респондентов демонстрирует недоверие к его эффективности. Возможно, этот фактор выступает в качестве одного из деструктивных, препятствующих привлечению коллег в ряды членов профсоюзной организации.

Еще одним аспектом анализа, который требует внедрения дополнительных мер, стало отношение руководящего звена университета к взаимодействию с профсоюзом. Здесь показатели немного выше, однако необходимо учитывать, что данная категория сотрудников способна влиять на ситуацию в университете, связанную с различными аспектами жизнедеятельности вуза: учебной нагрузкой, оплатой труда, 
организацией приема и увольнения и т.д. Это ставит перед профсоюзной организацией задачу установления более тесных взаимодействий с руководством ЮФУ, выстраивания отношений уважения и повышения авторитета и доверия к профсоюзной организации.

\section{Направление развития профсоюзного движения}

Международная организация труда (МОТ) опубликовала доклад о настоящем и будущем трудовых отношений и возможных направлениях развития профсоюзного движения в мире. Исследование показало, что глобальной тенденцией десятилетия стало увеличение количества людей, занятых в неформальном секторе экономики, т.е. любой экономической деятельности, не учитываемой официальной статистикой (компании в этом секторе, как правило, не имеют статуса юридического лица, а работники официально не трудоустроены). Больше половины $(61,2 \%)$ из 3 млрд трудящихся по всему миру вовлечены в неформальную занятость.

Что это означает для системы образования? Во-первых, число желающих получить образование в вузе может снижаться. Уменьшение показателя официального трудоустройства может приводить к пропорциональному снижению финансирования государством количества мест на получение образования, что, в свою очередь, может сказаться на сокращении рабочих мест в системе образования.

Во-вторых, в последние годы наметилась тенденция выведения из системы образования всех непрофильных служб. Численность сотрудников учебных заведений существенно сократилась. В основном это низкоквалифицированный персонал, но государство ранее брало заботу о них на себя. В настоящее время они либо остались без работы, либо перешли в коммерческие структуры, где вопросы защиты трудовых прав могут стоять на последнем месте. И они точно не входят ни в один профсоюз.

По подтвержденным данным МОТ, существенное влияние на структуру рынка труда оказывает цифровизация. В ближайшем будущем значительно снизится число рабочих мест. Мы отмечаем эту тенденцию в системе образования, где все больше учебных курсов переводится в онлайн-формат. В условиях тотальной цифровизации в системе высшего образования растут риски, связанные с сокращением рабочих мест, что ставит новые задачи для профсоюзной организации в обеспечении социальной стабильности в вузе.

Сокращение рабочих мест на предприятиях, внедрение нестандартных форм занятости, массовое вовлечение трудящихся в нефор- 
мальный сектор экономики привели к тому, что по всему миру профсоюзные ряды тают. Сегодня из 3 млрд работников старше 15 лет в рабочих объединениях состоят лишь 516 млн (по данным МОТ). Независимые профессиональные союзы - лидеры по охвату членством сосредоточены в Северной Европе. Второе место занимает Северная Африка, а замыкают тройку Восточная и Центральная Европа.

Экспертами МОТ также зафиксирована еще одна тенденция спад членства в рабочих объединениях, который ведет к снижению в том числе протестной активности.

В ближайшее время профсоюзам предстоит ответить на вопрос, как новые технологии повлияют на трудовые отношения. У работников не меньше вопросов: чего ожидать от профессиональных союзов в ближайшие два десятилетия, останутся ли они крупными членскими организациями или будут представлять интересы меньшинства? Проанализировав текущее положение рабочих объединений в мире, эксперты МОТ представили вариант развития событий.

Наиболее благоприятный для профсоюзов способ укрепить свои позиции - это усовершенствовать структуру и омолодить коллектив. Эксперты МОТ отмечают необходимость поднять численность молодежи в профсоюзах как минимум вдвое. Вероятность такого развития событий высокая: сейчас профсоюзы внедряют новые форматы взаимодействия с трудящимися, активно осваивают интернетпространство, занимаются переобучением своих членов.

Это новые задачи, которые современное общество ставит перед профсоюзом. Профсоюз сегодня - не просто защитник сотрудников на забастовках и акциях протеста, а деловой партнер, профессиональное сообщество, способное выдвигать предложения и уметь их отстаивать по сохранению и приумножению рабочих мест и мест для получения профессии.

Приходится признать, что выводы и предложения, сделанные экспертами МОТ, отражают реальность и в российской системе образования и профсоюзном движении. Мы должны услышать эти рекомендации и сделать выводы, направленные на совершенствование системы защиты прав работников и обучающихся.

\section{Заключение}

В XXI в. идеи солидарности актуальны как никогда. Только объединенные, аргументированные, профессионально сформулированные требования могут быть услышаны. Профсоюзу в настоящее время необходимо не только ставить задачи по защите трудовых прав работни- 
ков, но и искать пути сохранения рабочих мест, формирования легальной занятости, эффективных средств мотивации членства в правозащитной организации, брать функции по воспитанию молодежи и социальной поддержке.

ППО ЮФУ, подойдя к своему столетнему юбилею, находится в общем векторе не только федерального, но и мирового развития. Проблемы и вопросы у нас общие, цели и задачи мы также должны формулировать вместе. Только опираясь на профессиональное сообщество заинтересованных коллег, мы сможем укрепить позиции правозащитного движения, а значит, сделать работу и учебу в системе образования комфортнее на последующие 100 лет.

\section{Литература}

Волков Ю.Г. Солидарная активность в российском обществе: креативные практики // Социологические исследования. 2017. № 2. C. 41-48.

Кожевникова М.Н. Протестность и солидарность в образовании // Социум и власть. 2014. № 2 (46). С. 24-29.

Конституция РФ // Собрание законодательства РФ. 2014. № 31. Ст. 4398.

Нехода Е.В., Чувакин В.С. Профессиональные союзы наемных работников: вчера, сегодня, завтра // Вестник Томского гос. унта. Экономика. 2010. № 4 (12). С. 77-86.

Публичные отчёты ЦС профсоюза // Общероссийский профсоюз образования. Режим доступа: https:// www.eseur.ru/ public_reports/.

Резниченко М.Г. История профсоюзной организации Ростовского государственного университета. Ростов н/Д., 2008. 150 с.

Резниченко М.Г. История профсоюзной организации Южного федерального университета. 2-е. изд., доп. и перераб. Ростов н/Д.: Foundation, 2015. 180 с.

Самарская E. Наука и идеология солидарности // Философская антропология. 2016. № 1.

Сборник материалов социологических исследований, проводимых ППО ЮФУ / под ред. С.А. Дюжикова, Л.А. Савченко, В.М. Семигука. 2-е изд., доп. Ростов н/Д.; Таганрог: Изд-во Южного фед. ун-та,

\section{References}

Volkov, Yu.G. (2017). Solidarity activity in Russian society: creative practices. Sotsiologicheskiye issledovaniya, 2, 41-48. (in Russian).

Kozhevnikova, M. N. (2014). Protest and solidarity in education. Sotsium $i$ vlast', 2 (46), 24-29. (in Russian).

The Constitution of the Russian Federation (2014). Collection of legislation of the Russian Federation, 31, art. 4398. (in Russian).

Nekhoda, E.V., Chuvakin, V.S. (2010). Trade unions of employees: yesterday, today, tomorrow. Vestnik Tomskogo gos. un-ta. Ekonomika, 4 (12), 77-86. (in Russian).

Public reports of the CA of the trade Union. All-Russian Trade Union of Education. Available at: https:// www.eseur.ru/public_ reports/. (in Russian).

Reznichenko, M.G. (2008). History of the trade Union organization of the Rostov State University. Rostov n/D. (in Russian).

Reznichenko, M.G. (2015). History of the trade Union organization of the southern Federal University. 2nd ed., additional and rewrite. Rostov n/D.: Foundation. (in Russian).

Samarskaya, E. (2016). Science and ideology of solidarity. Filosofskaya antropologiya, 1. (in Russian).

Collection of materials of sociological research conducted by the SFU Trade Union (2018). S.A. Duzhikov, L.A. Savchenko, V.M. Semiguk (Eds.). 2nd ed., additional. Rostov n/D.; Taganrog: Southern Federal 
2018. T. 2. $140 \mathrm{c.}$

Скрипникова М.И., Смирнов Ю.И., Александрова E.B. Профсоюз и работодатель // Вестник РЭА им. Г.В. Плеханова. 2018. № 1 (97). С. 204-209.

Соколов Н. Краткий очерк истории Всероссийского союза учителей и деятелей по народному образованию // Вестник Всероссийского союза учителей и деятелей по народному образованию. 1905. № 2.

Федеральный закон от 12.01.1996 № 10-Ф3 «О профессиональных союзах, их правах и гарантиях деятельности» // Российская газета. 1996. № 12. 20 янв.
University Press, 2. (in Russian).

Skripnikova, M.I., Smirnov, Yu.I., Alexandrova, E.V. (2018). Trade Union and employer. Vestnik REA imeni G. V. Plekhanov, 1 (97), 204-209. (in Russian).

Sokolov, N.A. (1905). Brief outline of the history of the all-Russian Union of teachers and figures in public education. Vestnik Vserossiyskogo soyuza uchiteley $i$ deyateley po narodnomu obrazovaniyu, 2. (in Russian).

Federal law of 12.01.1996 N 10-FZ "On trade unions, their rights and guarantees of activity" (1996). Rossiyskaya Gazeta, 12, January 20. (in Russian). 